Motrivivência v. 29, n. 50, p. 104-122, maio/2017

\title{
POSSIBILIDADES DE REALIZAÇÃO DO DIAGNÓSTICO NO ENSINO DOS ESPORTES: uma pesquisa-ação com professores de Educação Física
}

\author{
Robson Machado Borges' \\ Adroaldo Cezar Araujo Gaỵa² \\ Fernando Jaime González ${ }^{3}$ \\ Larissa Rafaela Galatti ${ }^{4}$
}

\begin{abstract}
RESUMO
Este estudo teve por objetivo descrever como as possibilidades de diagnóstico de um jogo com interação entre adversários são condicionadas pela compreensão da lógica interna dos esportes. Para tanto, foi desenvolvida uma pesquisa-ação com cinco professores de Educação Física que desenvolvem o ensino dos esportes. Foram realizados 21 encontros de estudos sobre a decisão de o que ensinar quando o foco é o conhecimento procedimental do conteúdo. Os resultados indicam que o nível de leitura das dificuldades dos alunos no jogo depende diretamente do conhecimento do professor sobre a lógica interna das modalidades, o que afeta o aprendizado dos discentes. Não obstante, é possível alterar a forma como os professores compreendem o ensino dos esportes, fazendo com que docentes que realizam a leitura do jogo sob a ótica do modelo tradicional compreendam o fenômeno esportivo como um complexo processo de tomada de decisões, ensinando os alunos a jogar melhor.
\end{abstract}

Palavras-chave: Esporte; Concepção de Ensino; Diagnóstico; Mudança

1 Mestre em Ciências do Movimento Humano. Professor do curso de Educação Física na Universidade Regional do Noroeste do Estado do Rio Grande do Sul (Unijuí). Ijuí/Rio Grande do Sul, Brasil.

E-mail: robson.borges@unijui.edu.br

2 Doutor em Educação Física e em Ciência do Desporto. Professor da Universidade Federal do Rio Grande do Sul. Porto Alegre/Rio Grande do Sul, Brasil. E-mail: acgaya@esef.ufgrs.br

3 Doutor em Ciências do Movimento Humano. Professor da Universidade Regional do Noroeste do Estado do Rio Grande do Sul (Unijuí). Ijuí/Rio Grande do Sul, Brasil. E-mail: fjg@unijui.edu.br

4 Doutora em Educação Física. Professora do curso de Ciências do Esporte da Faculdade de Ciências Aplicadas da Universidade Estadual de Campinas (FCA/UNICAMP). Limeira/São Paulo, Brasil. E-mail: lagalatti@hotmail.com 


\section{INTRODUÇÃO}

O esporte é um dos fenômenos culturais mais ensinados para crianças e jovens em nossa sociedade. No entanto, diferentes autores, de diversos países (BAYER, 1994; CÔTÉ; HANCOCK, 2014; GARGANTA, 2004; GRAÇA; MESQUITA, 2006; GRIFFIN; MITCHELL; OSLIN, 1997; KIRK; MACPHAIL, 2002; LIGHT; TAN, 2006; SIEDENTOP, 2002; TAVARES, 2013, entre outros) têm apontado que a forma como os esportes têm sido convencionalmente ensinados, dificulta aos alunos uma atuação de forma proficiente ${ }^{5}$, dentro de um nível recreativo e/ou de lazer.

A referida forma de ensino tem sido realizada, na maioria das vezes, através de uma abordagem tradicional, isto é, tem a dimensão técnica como centralidade das aulas, desconsiderando a dimensão tática (GARGANTA, 2004; GRAÇA; MESQUITA, 2006). De acordo com Ramos, Graça e Nascimento (2006, p. 38), trata-se de uma forma de ensino sustentada num "pensamento mecanicista". Para Mesquita (2013, p. 103), na abordagem tradicional

[...] a prática é organizada, não raramente, em formas de jogo desestruturadas ou no jogo formal, em que a execução técnica é aplicada de forma isolada e descontextualizada, em que a instrução é centrada na componente técnica, com pouca relevância para as exigências do jogo e em que os elementos críticos de um jogo de qualidade são desvalorizados.

Na mesma linha conceitual, Mesquita e Graça (2006, p. 271) indicam que "as abordagens tradicionais ao ensino dos jogos se centram na instrução fragmentária e inerte das habilidades técnicas". Em contraposição, os autores asseveram que o jogo deve ser o "centro de atenção das aprendizagens, valorizando a compreensão do jogo como porta de entrada para o desenvolvimento da competência, subordinando a aprendizagem das habilidades técnicas à necessidade de as usar no jogo" (ibidem, p. 271).

No mesmo sentido, Graça (2013) aponta que é um engano supor que o ensino dos jogos esportivos se limita à instrução de habilidades isoladas. O autor afirma que

[...] aquilo que parece ser uma autoevidência, isto é, se não ensinarmos previamente as habilidades do jogo, os alunos não serão capazes de jogar, tem sido a maior falácia das didáticas do ensino dos jogos, porque o tempo gasto a aprender habilidades isoladas nunca ou muito pouco se converte em ganhos para o jogo. A transferência das aprendizagens para o jogo, pura e simplesmente não acontece (ibidem, p. 90).

Com base nas ideias apresentadas, é possível pensar que o ensino dos esportes centrado na ótica da perspectiva técnica ${ }^{6}$ não se sustenta na contemporaneidade. Garganta

5 Na perspectiva de González e Fraga (2009, p. 178), "este conceito é sinônimo de: competente, capaz, hábil. Ser proficiente numa prática corporal significa poder dar conta das exigências colocadas quando de sua realização no contexto do lazer. Trata-se de um grau de domínio da prática que permite ao sujeito 'se virar' quando a realiza".

6 Não consideramos a confrontação direta uma forma de ensino intencional. 
(1998) considera que, neste panorama de ensino dos esportes, as reais situações de jogo são pobres e podem prejudicar a aprendizagem do aluno, pois suas consequências mostram um jogo pouco criativo, com problemas de compreensão e comportamentos comuns. No mesmo viés, o autor defende que a "tecnificação do ensino e treino tem constituído um entrave à evolução dos praticantes, nomeadamente no que concerne à construção de um jogar inteligente" (idem, 2004, p. 219).

Contrariamente à referida forma de conceber os esportes, os modelos de ensino ${ }^{7}$ centrado na tática se pautam nas reais dificuldades dos alunos na atuação nos jogos esportivos. Nessa perspectiva, uma atitude inevitável ao docente, ao pensar o desenvolvimento dos esportes, é decidir quais conteúdos propor nas aulas quando o foco é o conhecimento procedimental (ZABALA, 1998), ou, simplificando em uma pergunta: o que ensinar aos alunos? Costumeiramente, muitos professores optam por conteúdos com os quais se sentem mais à vontade, que têm mais facilidade para desenvolver (GONZÁLEZ; BORGES, 2015). Desse modo, os saberes oportunizados aos alunos acontecem de acordo com o gosto do educador.

No viés dos modelos de ensino centrado na tática, uma ferramenta essencial para responder à pergunta anterior é a realização do diagnóstico. Trata-se de uma análise do nível do desempenho dos alunos, visando a aferir os problemas que atrapalham o sucesso no jogo. Segundo González e Fraga (2012, p. 144), "um procedimento fundamental para o início de qualquer unidade didática ${ }^{8}$ é diagnosticar os saberes prévios dos alunos sobre os assuntos que serão estudados". De acordo com González e Bracht (2012, p. 97), o diagnóstico "trata-se de uma avaliação inicial com a qual se busca distinguir quais são os conhecimentos prévios dos alunos sobre o que se pretende ensinar e, simultaneamente, suas maiores dificuldades para dar conta das exigências do jogo".

Com essa compreensão, é possível realizar uma analogia entre o diagnóstico realizado pelo docente ao trabalhar com o ensino dos esportes e o diagnóstico de um médico. Ao atender um paciente, o médico busca identificar, através dos sintomas, os problemas que estão importunando o indivíduo e, com base no diagnóstico, receita medicamentos para solução do problema. Se o médico não receitar a medicação de acordo com o resultado do diagnóstico, o paciente não será curado, podendo até mesmo ter seu quadro clínico agravado. No caso do professor de Educação Física, a análise dos alunos no jogo serviria para verificar as dificuldades e, de acordo com esse diagnóstico, propor os conteúdos para que os discentes possam melhorar seu desempenho no jogo. Se porventura os conteúdos

7 González (2008, p. 26) entende por modelo de ensino dos esportes o "[...] conjunto de concepções ou ideias sobre os elementos diretamente envolvidos numa proposta de ensino-aprendizagem de modalidades esportivas pelo qual se procuram entender/organizar os diversos procedimentos possíveis dentro desse processo (concepções sobre: o praticante/sujeito de aprendizagem, a relação conhecimento dos alunos e atuação, o processo de aprendizagem, as práticas esportivas coletivas com interação, o elemento técnico, o elemento tático individual, a relação entre o elemento técnico e o elemento tático individual, tipos de procedimentos didáticos, a sequência de apresentação de conteúdos, entre outros)".

8 No entendimento de González e Bracht (2012), unidade didática corresponde a ação de, após definir os conteúdos, organizar e distribuir os assuntos ao longo do período que será dedicado ao aprendizado dos alunos. Trata-se do processo de evidenciar o conteúdo/objetivo de cada aula. 
ensinados aos alunos não corresponderem ao resultado do diagnóstico, os discentes dificilmente terão oportunidade de superar suas dificuldades. Ou ainda, no caso de ensinar uma habilidade técnica de forma isolada quando o problema é tático, "até podemos pensar que prejudica, já que busca automatizar um comportamento que não é precedido por uma leitura da situação, o que pode dificultar mais ainda que o aluno aprenda a observar antes de agir" (GONZÁLEZ; BRACHT, 2012, p. 33).

Nessa perspectiva, parte-se do entendimento de que antes de ensinar determinados conteúdos de uma modalidade esportiva, o professor deve realizar um diagnóstico para identificar as dificuldades que comprometem o desempenho dos alunos durante o jogo. Desse modo, a seleção dos conteúdos ocorrerá segundo as necessidades reais dos discentes.

Segundo González e Fraga (2012, p. 81), a realização do diagnóstico permite "a identificação dos principais problemas, a construção de objetivos exequíveis e a proposição de uma sequência adequada dos temas em estudo". Os mesmos autores argumentam que "cada professor precisa avaliar o que os estudantes de fato sabem sobre o assunto para calibrar a relação ensino-aprendizagem de acordo com a especificidade de sua turma" (ibidem, p. 81). Nesse sentido, é imprescindível que o professor/treinador tenha capacidade para identificar os principais erros dos alunos, bem como as circunstâncias presentes na origem da ação da jogada (GARGANTA, 2006). Desse modo, os conteúdos a serem ensinados aos discentes, "[...] dependem da seleção feita pelo professor depois de aferir o nível de conhecimento prévio de seus alunos sobre o assunto" (GONZÁLEZ; FRAGA, 2012, p. 78).

Para realizar a avaliação diagnóstica, González e Fraga (2012, p. 101) sugerem que se "coloque a turma a jogar para ver como se saem" precisa ter as mesmas características do jogo formal da modalidade. Por exemplo, se a modalidade proposta for o futsal, quando a equipe estiver no ataque, precisará: manter a posse da bola, progredir na quadra de ataque e construir situações para finalizar. Nesse sentido, os referidos autores recomendam jogos "em escala reduzida"10 (3v3 ou 4v4) ${ }^{11}$. Para tal atividade, "é recomendável orientar os alunos a realizarem marcação individual ('cada um marca o seu')" (ibidem, p. 101).

O processo de realização do diagnóstico pode ser separado em três momentos: identificação, priorização e seleção. O primeiro deles, diz respeito à identificação de todas as dificuldades dos alunos durante o jogo. Basicamente, consiste em analisar os entraves sobre três aspectos: a) normativo; b) de ordem técnica; c) de ordem tática.

$\mathrm{O}$ aspecto normativo vincula-se às regras do jogo. Logo, se o esporte desenvolvido for o basquetebol, por exemplo, será uma dificuldade do aluno o fato de ele se deslocar segurando a bola (sem quicar), sair correndo com a bola na mão.

Os entraves de ordem técnica estão relacionados às execuções incorretas de gestos motores. Podem ser citados como exemplo, quando os alunos: não conseguem

9 Os autores indicam a realização de uma filmagem do jogo.

10 Em uma quadra de $40 \mathrm{~m} \times 20 \mathrm{~m}$, poderia ser realizado o jogo em um quarto da quadra, imaginando a quadra dividida em quatro partes iguais, assim haveria quatro jogos entre oito equipes.

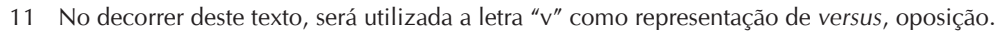


recepcionar a bola, realizam o passe muito forte, estando livres de marcação - próximos ao objetivo - finalizam errado.

As dificuldades de ordem tática, por sua vez, normalmente são as que mais atrapaIham os alunos de obter sucesso no jogo. São problemas de intenções táticas, por exemplo, quando os participantes apresentam dificuldades em observar antes de agir, progredir com a equipe para o ataque, desmarcar-se para receber a bola.

O segundo passo do diagnóstico consiste em priorizar as dificuldades dos alunos verificadas, utilizando o critério de importância. Por isso, é necessário levar em conta a expressão dificuldades dos discentes que mais comprometem o desempenho esportivo. De acordo com González e Fraga (2012, p. 81), "saber o que os alunos conseguem fazer dentro de um campo de jogo e, particularmente, identificar qual dificuldade mais atrapalha suas possibilidades de desempenho é fundamental para decidir o que é prioritário ensinar".

Nessa linha, a priorização das dificuldades ocorre de acordo com uma lógica de desenvolvimento dos conteúdos. Trata-se de uma escolha que o professor realiza. Por exemplo, ao planejar uma unidade didática para uma turma iniciante, o docente precisará definir qual a sequência dos assuntos que será trabalhada, estipulando o conteúdo da primeira aula, o tema da segunda, e assim sucessivamente. Mais precisamente, necessitará decidir, por exemplo, se proporciona aos alunos primeiramente a intenção tática passar ao jogador desmarcado ou os movimentos de dribles.

Finalmente, o terceiro passo consiste na realização da seleção dos conteúdos que serão ensinados aos alunos. O número de assuntos abordados depende das dificuldades priorizadas e do número de aulas que serão destinadas para uma unidade didática. Por exemplo, caso a unidade didática tenha 20 aulas, não seria consentâneo trabalhar mais do que dez dificuldades - que são transformadas em conteúdos -, pensando em uma lógica de no mínimo duas aulas para cada conteúdo, o que é bem pouco para algumas intenções táticas $^{12}$, dependendo da idade e da experiência dos alunos.

É importante que a sequência dos conteúdos, na medida do possível, seja pensada de forma progressiva, pois facilita a evolução do nível de desempenho dos alunos no jogo. No entanto essa organização não deve obedecer uma hierarquização de forma rígida (GRAÇA; MESQUITA, 2013), uma vez que os discentes podem aprender um conteúdo mais rapidamente do que outro. Na parte que segue, consta a demonstração de um diagnóstico realizado visando o ensino da modalidade basquetebol, que contempla os três momentos aqui abordados.

12 Algumas intenções táticas, como desmarcar-se para receber a bola, por exemplo, apresentam um grau de complexidade maior do que outras, o que dificulta o aprendizado do aluno, demandando um número maior de aulas para efetivamente conseguir uma melhora no desempenho. 
V. $29, n^{\circ} 50$, maio/2017

Quadro 1 - Diagnóstico em três momentos

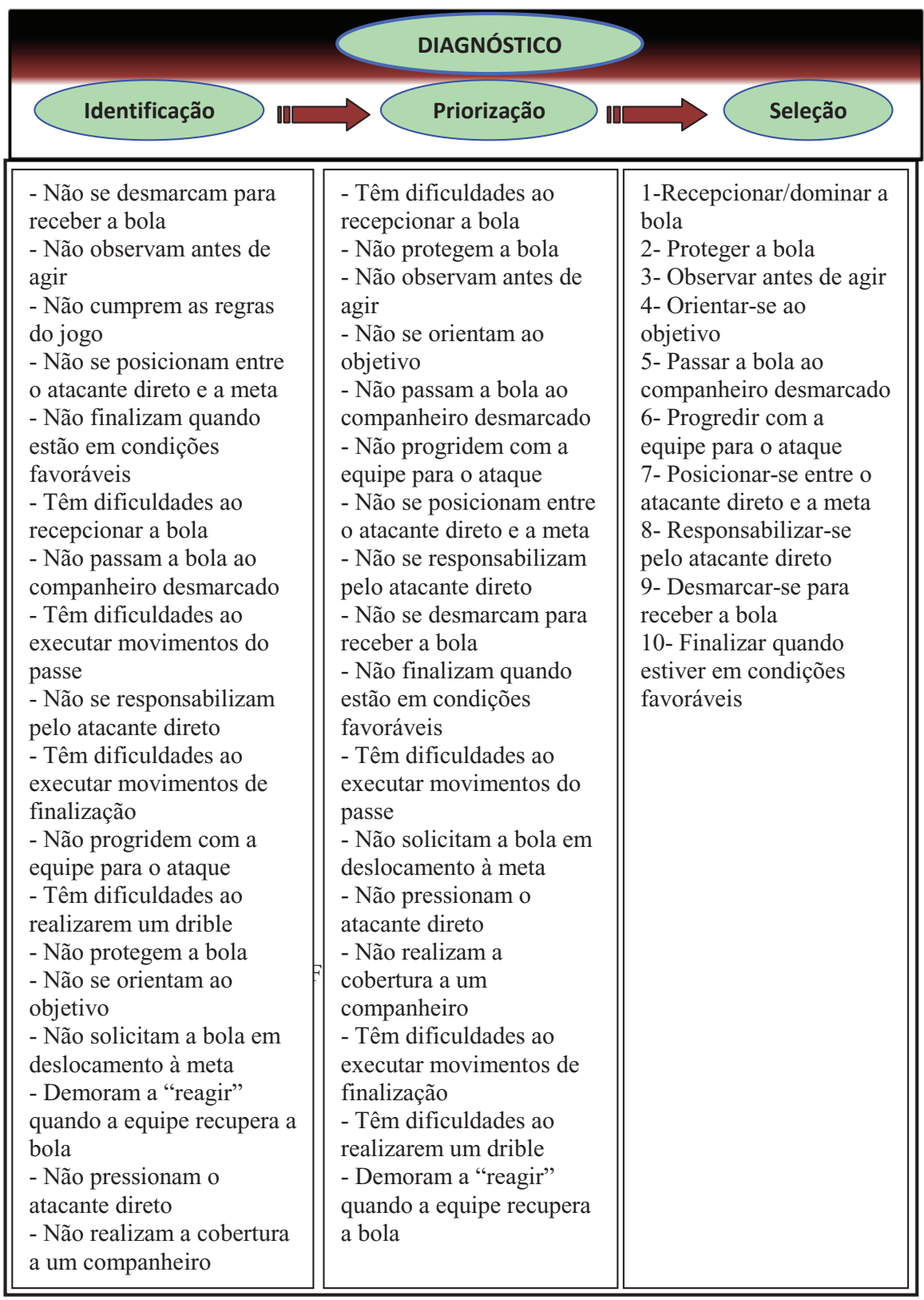

Fonte: os autores (2016) 
As dificuldades observadas através do diagnóstico têm ligação direta com os subpapéis dos jogos esportivos de invasão ${ }^{13}$. Por exemplo, a intenção tática posicionar-se entre o atacante que está marcando e a meta que defende é uma ação esperada de um defensor. Logo, esse assunto é de suma importância no ensino dos esportes. González e Bracht (2012) apresentam uma divisão dos subpapéis em quatro funções: atacante com posse de bola, atacante sem posse de bola, defensor do atacante com posse de bola e defensor do atacante sem posse de bola.

Para facilitar o entendimento sobre os subpapéis, segue o seguinte exemplo: se imaginarmos um jogo de basquetebol - 5v5 -, cada um dos dez jogadores em quadra sempre estará na condição de um subpapel. Ou seja, se a equipe do jogador A estiver com a posse da bola, mas a bola não estiver com o jogador A, ele será um atacante sem posse de bola. Se a bola estiver com o jogador A, ele desempenhará o subpapel de atacante com posse de bola. Do contrário, se a equipe adversária estiver com a posse da bola, o jogador A será um defensor. Nessa lógica, se o jogador marcado por A estiver com a posse da bola, ele será um defensor do atacante com posse de bola. Caso o jogador marcado por A não estiver com a posse da bola, ele será um defensor do atacante sem posse de bola.

A compreensão da existência e do funcionamento dos subpapéis é importante para proporcionar um aprendizado de qualidade ao aluno, pois em cada subpapel o jogador tem escolhas a fazer. Por exemplo, se o jogador estiver na condição de atacante com posse de bola, ele terá que decidir, muitas vezes em fração de segundos, se: a) passa a bola, nesse caso, para quem, como, quando, qual o tipo de passe, qual a força empregada na ação; b) arremessa, o que o levará a pensar quando e qual o tipo de arremesso; c) dribla, consequentemente, quando, para que lado, qual drible; d) progride com a bola, com isso, qual altura do quique da bola, qual lado, qual direção, que velocidade será imprimida.

Utilizando outro subpapel como exemplo, se o jogador desempenhar a função de atacante sem posse de bola, ele precisará optar entre: a) progredir com a equipe para o ataque; b) desmarcar-se para receber a bola, nesse caso, escolher quando, o espaço do local de jogo - próximo ou longe do companheiro com bola -, o tipo de deslocamento (cortes em L ou V, por exemplo), a direção do deslocamento - em direção ao objetivo ou para o lado -, o momento em que solicitará a bola; c) realizar bloqueio sobre o adversário, o que levará a pensar quando, qual lado do adversário, se o bloqueio será estático ou dinâmico; d) ficar parado ocupando uma posição específica.

Portanto cada subpapel implica escolher uma opção entre as várias existentes. Como os jogadores mudam constantemente de função durante o jogo, o professor precisa compreender as distintas possibilidades de ações cognitivas e motoras possíveis e necessárias em cada subpapel.

Nessa perspectiva, entendemos que o ensino dos assuntos mencionados - entre outros - são fundamentais para uma atuação qualificada no jogo. No entanto, estudos

13 Esportes de invasão são aqueles em que os competidores tentam invadir o setor defendido pelos adversários para postar um móvel (geralmente uma bola) e marcar pontos, gols ou cestas, ao passo que precisam proteger sua própria meta. Futebol, polo aquático, hóquei na grama são exemplos. 
mostram que as vivências pré-universitárias e a própria formação acadêmica não colaboram para o aprendizado desses temas (COUTINHO; SILVA, 2009; RAMOS; GRAÇA; NASCIMENTO, 2006). Nesse sentido, Coutinho e Silva (2009, p. 117) apontam que "a metodologia tradicional tecnicista ainda é a mais utilizada por ter feito parte da formação profissional dos professores". Os mesmos autores afirmam que "o ensino dos esportes não vem sendo desenvolvido a contento na formação profissional com consequências negativas na educação básica" (ibidem, p. 130). No mesmo viés, González e Fraga (2012, p. 78) salientam que "o ensino do esporte centrado na tática individual não é muito usual entre os professores".

Além dos problemas na formação inicial ${ }^{14}$, a formação continuada oferecida não consegue ter efeito suficiente, pois não proporciona alternativas de mudança. Visando auxiliar os professores na mudança de concepção em relação aos esportes, a formação permanente deveria apresentar uma nova perspectiva, em que sua metodologia permitisse colocar os docentes frente a uma forma atual de ensino dos esportes, pautada nas constantes tomadas de decisões que ocorrem em um jogo esportivo com interação entre adversários. Como afirmam Mesquita e Graça (2006, p. 269),

[...] o alargamento da base de conhecimento sobre o jogo tem que ser acompanhado de uma ação de mudança conceitual sobre o ensino do jogo e de indução de uma disposição afetiva favorável a essa mudança. Conhecimento, competência e confiança, e ver para crer e fazer constituem os mecanismos para o sucesso dessa mudança.

Nesse sentido, Ferreira (2009, p. 164), após entrevistar e observar aulas de basquetebol ministradas por um grupo de professores, concluiu que "novas investigações precisam tratar a temática e necessitam, sobretudo, chegar ao alcance dos professores". A sugestão do autor é "a realização de ações de formação continuada com professores de iniciação esportiva, no sentido de proporcionar um maior enriquecimento no processo pedagógico, em ambientes de educação não formal" (ibidem, p. 164).

Nesse processo de busca de uma transformação na compreensão dos professores através da formação continuada, uma perspectiva que tem sido apontada como consistente e eficaz é a pesquisa-ação. Tripp (2005) defende que a pesquisa-ação é uma estratégia para o aperfeiçoamento de professores, buscando o aprimoramento do ensino, em prol do aprendizado dos alunos. No mesmo sentido, Franco (2005) afirma que a pesquisa-ação é eminentemente pedagógica e tem como objetivo a formação contínua dos envolvidos na prática. Seu foco consiste em "produzir transformações de sentido, ressignificações, ao que fazemos ou pensamos" (ibidem, p. 500).

Partindo da inquietação gerada pelo encadeamento das ideias apresentadas, um campo de estudo pertinente é a interpretação da compreensão dos sentidos e significados

14 De forma geral, as críticas realizadas ao trabalho do professor de Educação Física têm ocorrido desde a década de 1980, denunciando a má qualidade da atuação docente. Na maior parte dessas críticas, é mais fácil perceber o que não deve ser realizado, do que o apontamento de o que fazer (BETTI, 2013), ou o que González e Fensterseifer (2009) denominam didática da negativa. 
dos docentes no processo de ensino dos esportes. A partir desse entendimento, julgamos necessário tentar contribuir para uma mudança na visão dos professores a respeito do tema, pois um professor não poderá mobilizar saberes que não teve a oportunidade de conhecer/aprender. Logo, faz-se indispensável estudar com os docentes, propiciando-Ihes a reflexão e o contato com temas imprescindíveis para a realização de um ensino que permita aos alunos a apropriação do conhecimento procedimental dos esportes com interação entre adversários.

Tendo o contexto apresentado como preocupação, este estudo teve por objetivo descrever como as possibilidades de diagnóstico de um jogo com interação entre adversários são condicionadas pela compreensão da lógica interna dos esportes.

\section{PROCEDIMENTOS METODOLÓGICOS}

A investigação proposta está pautada em uma abordagem qualitativa, com foco na interpretação, no significado e no sentido do trabalho docente. Mais especificamente, caracteriza-se como uma pesquisa-ação, na qual o sujeito-pesquisador participa diretamente das reflexões acerca do trabalho. De acordo com Thiollent (2011, p. 20), trata-se de

[...] um tipo de pesquisa social com base empírica que é concebida e realizada em estreita associação com uma ação ou com a resolução de um problema coletivo e no qual os pesquisadores e participantes representativos da situação ou do problema estão envolvidos de modo cooperativo ou participativo.

Para Betti (2010, p. 142), a pesquisa-ação diz respeito à "pesquisa na qual as pessoas envolvidas têm participação ativa, e na qual há uma exigência de conhecimento a ser produzido". Essa necessidade de evolução não está relacionada apenas com a resolução de um problema prático da melhor maneira - busca melhorar a prática educativa (idem, 2013).

O processo de investigação ocorreu em 21 encontros de um grupo de estudos formado por um dos pesquisadores e cinco docentes com formação em Educação Física, os quais desenvolvem o ensino dos esportes no Programa Atleta do Futuro do Serviço Social da Indústria, nas regiões Centro-Leste e Metropolitana de Porto Alegre, no Rio Grande do Sul. Desses, quatro são do gênero masculino e uma do gênero feminino ${ }^{15}$.

Nos encontros de estudos (com o tempo de 1h30min aproximadamente ${ }^{16}$ ) o pesquisador integrante do grupo atuou como mediador de diálogos críticos-reflexivos, de modo que o conjunto de professores pôde expressar suas representações sobre as concepções

15 O grupo de docentes partícipes se caracteriza pela heterogeneidade quanto à idade (de 27 a 45 anos), à instituição na que realizaram a formação inicial (três universidades diferentes), ao período de conclusão da graduação (de 2005 a 2009), ao tempo de experiência docente (de 5 a 15 anos), à formação de pós-graduação (graduação a mestrado) e à relação com o esporte (jogador amador de basquetebol, proprietário de uma escolinha de futsal, jogador de voleibol profissional, treinador de equipe de futsal e vivência em jogos escolares).

Os encontros ocorreram na empresa em que os professores trabalham, em horário de trabalho. 
que possuem acerca do ensino dos esportes. Metodologicamente, o grupo dialogou sobre diversos assuntos considerados - pelos pesquisadores - essenciais no desenvolvimento dos esportes e outros temas que os docentes propuseram ${ }^{17}$. Esses encontros consistiram em reuniões e seminários, ocorrendo uma vez por semana. Nesse processo, buscou-se a construção de saberes através de um processo coletivo, levando em consideração os saberes atuais dos professores.

Como instrumentos para levantamento de dados durante os encontros, utilizou-se: a) as gravações das falas dos sujeitos; b) as filmagens dos encontros do grupo de estudos; c) as anotações realizadas pelos docentes, as quais foram recolhidas ao final das reuniões; e) os registros, em um diário de campo, sobre as falas, manifestações, depoimentos e comportamentos dos professores ${ }^{18}$.

No que se refere aos cuidados éticos, este estudo foi aprovado pelo Comitê de Ética em Pesquisa da Universidade Federal do Rio Grande do Sul, sob parecer de número 535.88. Cabe ressaltar que visando a preservar a identidade dos participantes da investigação, os nomes dos professores foram substituídos por prenomes fictícios (Alberto, Cláudia, Danilo, Pedro e Ricardo).

\section{ANÁLISE DOS DADOS E DISCUSSÃO DOS RESULTADOS}

A análise comparativa dos diagnósticos realizados pelos docentes, antes e após os estudos, foi realizada com base em uma análise de conteúdo. Através dessa ferramenta, buscamos identificar os núcleos de sentido com base em Silverman (2009), quando o autor aponta que na análise de conteúdo os pesquisadores costumam estabelecer um conjunto de categorias definidas, sendo que, particularmente na pesquisa qualitativa, utilizam-se trechos e recortes não tabulados que ilustram categorias em particular. Desse modo, organizamos as informações de um grupo de elementos que compõem o conjunto dos diagnósticos e sistematizamos esses dados em uma matriz de análise, para possibilitar a visualização e a compreensão das informações de forma mais consistente. Nessa oportunidade, os docentes realizaram a análise de um vídeo, de uma turma de alunos, em um jogo $3 \mathrm{v} 3$.

Na comparação dos resultados dos diagnósticos de um jogo com estrutura funcional, é possível apontar que a compreensão do modelo de ensino e dos processos de regulação dos desempenhos dos alunos durante o jogo condiciona as possibilidades de diagnóstico das dificuldades dos jogadores e, consequentemente, afeta o processo de ensino. Dito de outra forma, se no diagnóstico não se identifica mais do que problemas na execução

17 Os assuntos estudados nos encontros, pautados na proposta de González e Bracht (2012), foram os seguintes: elementos do desempenho esportivo (tática, técnica, estratégia, sistema de jogo, capacidade física, capacidade volitiva e combinação tática); lógica interna; mecanismos de processamento da informação; subpapéis dos esportes de invasão; habilidades motoras; modelos de ensino; diagnóstico; métodos de ensino; tipos de tarefas; intervenção do professor; papel do aluno.

18 Anteriormente aos encontros, entrevistas foram realizadas com os participantes buscando conhecer a trajetória de cada um, vinculada ao esporte. 
técnica, o ensino, coerentemente, será orientado para superar essas dificuldades. Contudo, no caso observado, isso não seria o mais consentâneo, no momento em que a maioria das dificuldades apresentadas - além do critério de mais comprometer o desempenho dos participantes - se vincula com a tática individual e, consequentemente, a outro formato de trabalho. Na sequência, apresentamos as comparações entre os diagnósticos realizados pelos docentes.

Quadro 2 - Matriz de análise dos diagnósticos realizados pelo professor Alberto

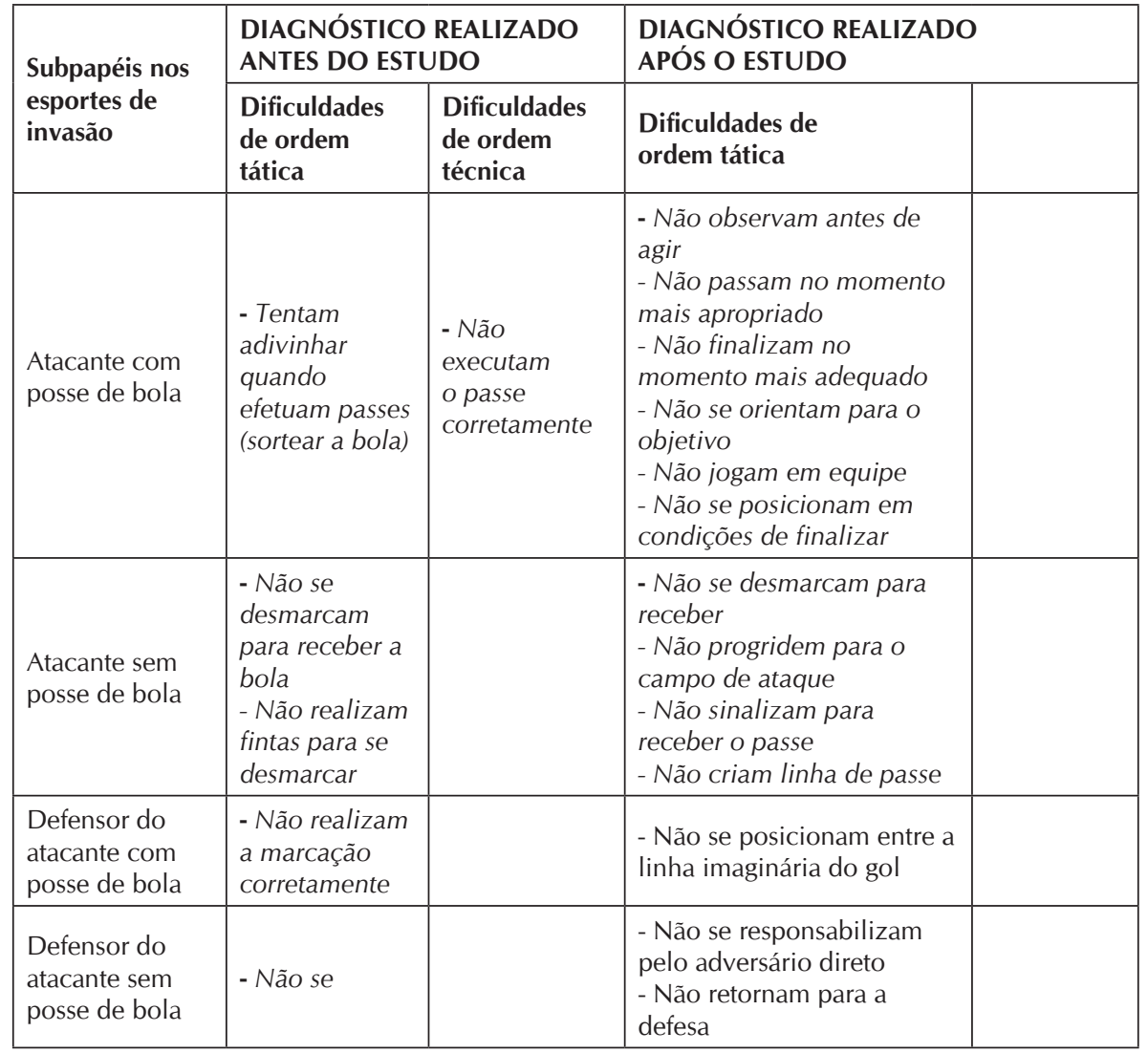

Fonte: os autores (2016)

Ao analisar os dois diagnósticos realizados pelo professor Alberto, é possível observar que ele conseguiu identificar mais do que o dobro de dificuldades que havia percebido na primeira observação. Além de a centralidade das falhas dos alunos corresponder à dimensão tática, no segundo diagnóstico Alberto apontou no mínimo duas intenções táticas para cada subpapel. 
V. $29, n^{\circ} 50$, maio/2017

Quadro 3 - Matriz de análise dos diagnósticos realizados pela professora Cláudia

\begin{tabular}{|c|c|c|c|c|}
\hline \multirow{2}{*}{$\begin{array}{l}\text { Subpapéis nos } \\
\text { esportes de } \\
\text { invasão }\end{array}$} & \multicolumn{2}{|c|}{$\begin{array}{l}\text { DIAGNÓSTICO REALIZADO } \\
\text { ANTES DO ESTUDO }\end{array}$} & \multicolumn{2}{|c|}{$\begin{array}{l}\text { DIAGNÓSTICO REALIZADO } \\
\text { APÓS O ESTUDO }\end{array}$} \\
\hline & $\begin{array}{l}\text { Dificuldades de } \\
\text { ordem tática }\end{array}$ & $\begin{array}{l}\text { Dificuldades } \\
\text { de ordem } \\
\text { técnica }\end{array}$ & $\begin{array}{l}\text { Dificuldades de } \\
\text { ordem tática }\end{array}$ & $\begin{array}{l}\text { Dificuldades } \\
\text { de ordem } \\
\text { técnica }\end{array}$ \\
\hline $\begin{array}{l}\text { Atacante com } \\
\text { posse de bola }\end{array}$ & $\begin{array}{l}\text { - Passou a bola } \\
\text { para os colegas, } \\
\text { tendo demais } \\
\text { colegas livres }\end{array}$ & $\begin{array}{l}\text { - Passes } \\
\text { rápidos de } \\
\text { difícil acesso } \\
\text { para o colega }\end{array}$ & $\begin{array}{l}\text { - Não observam } \\
\text { antes de agir } \\
\text { - Não finaliza em } \\
\text { condições favoráveis } \\
\text { - Não passa a } \\
\text { bola ao jogador } \\
\text { desmarcado } \\
\text { - Não progride com } \\
\text { a bola }\end{array}$ & $\begin{array}{l}\text { - Não domina } \\
\text { a bola }\end{array}$ \\
\hline $\begin{array}{l}\text { Atacante sem } \\
\text { posse de bola }\end{array}$ & & & $\begin{array}{l}\text { - Não se desmarca } \\
\text { para receber a bola }\end{array}$ & \\
\hline $\begin{array}{l}\text { Defensor do } \\
\text { atacante com } \\
\text { posse de bola }\end{array}$ & & & $\begin{array}{l}\text { - Não se posiciona } \\
\text { entre o atacante e } \\
\text { o gol }\end{array}$ & \\
\hline $\begin{array}{l}\text { Defensor do } \\
\text { atacante sem } \\
\text { posse de bola }\end{array}$ & $\begin{array}{l}\text { - Equipe amarela } \\
\text { não faz marcação, } \\
\text { muito tempo na } \\
\text { defesa }\end{array}$ & & $\begin{array}{l}\text { - Não realiza a } \\
\text { marcação }\end{array}$ & \\
\hline
\end{tabular}

Fonte: os autores (2016)

No primeiro diagnóstico, a professora Cláudia havia identificado três falhas dos jogadores, para dois subpapéis. No segundo, percebeu oito erros, com ênfase na compreensão do jogo, contemplando os quatro subpapéis. 
Quadro 4 - Matriz de análise dos diagnósticos realizados pelo professor Danilo

\begin{tabular}{|c|c|c|c|c|}
\hline \multirow{2}{*}{$\begin{array}{l}\text { Subpapéis } \\
\text { nos esportes } \\
\text { de invasão }\end{array}$} & \multicolumn{2}{|c|}{$\begin{array}{l}\text { DIAGNÓSTICO REALIZADO } \\
\text { ANTES DO ESTUDO }\end{array}$} & \multicolumn{2}{|c|}{$\begin{array}{l}\text { DIAGNÓSTICO REALIZADO } \\
\text { APÓS O ESTUDO }\end{array}$} \\
\hline & $\begin{array}{l}\text { Dificuldades de } \\
\text { ordem tática }\end{array}$ & $\begin{array}{l}\text { Dificuldades de } \\
\text { ordem técnica }\end{array}$ & $\begin{array}{l}\text { Dificuldades de } \\
\text { ordem tática }\end{array}$ & $\begin{array}{l}\text { Dificuldades de } \\
\text { ordem técnica }\end{array}$ \\
\hline $\begin{array}{l}\text { Atacante com } \\
\text { posse de bola }\end{array}$ & & $\begin{array}{l}\text { - Passe muito forte } \\
\text { - Dificuldade em } \\
\text { receber a bola do } \\
\text { colega } \\
\text { - Deslocamentos } \\
\text { - Coordenação } \\
\text { motora, pé } \\
\text { esquerdo e domínio } \\
\text { (dificuldades) } \\
\text { - Passe } \\
\text { (dificuldades) }\end{array}$ & $\begin{array}{l}\text { - Não observam } \\
\text { antes de agir } \\
\text { - Não passam } \\
\text { para o aluno } \\
\text { desmarcado } \\
\text { - Não se } \\
\text { direcionam para o } \\
\text { objetivo } \\
\text { - Não finalizam } \\
\text { em condições } \\
\text { favoráveis }\end{array}$ & $\begin{array}{l}\text { - Não fazem } \\
\text { o passe } \\
\text { corretamente } \\
\text { - Não se } \\
\text { preocupam com } \\
\text { seu movimento } \\
\text { de drible } \\
\text { - Não conseguem } \\
\text { executar o } \\
\text { movimento de } \\
\text { deslocamento }\end{array}$ \\
\hline $\begin{array}{l}\text { Atacante sem } \\
\text { posse de bola }\end{array}$ & & & $\begin{array}{l}\text { - Não ficam entre } \\
\text { a linha imaginária } \\
\text { para o passe [linha } \\
\text { de passe] }\end{array}$ & \\
\hline $\begin{array}{l}\text { Defensor do } \\
\text { atacante com } \\
\text { posse de bola }\end{array}$ & & & $\begin{array}{l}\text { - Não ficam entre } \\
\text { o marcador e o } \\
\text { objetivo } \\
\text { - Não executam } \\
\text { a realização da } \\
\text { marcação correta } \\
\text { sobre o adversário }\end{array}$ & $\begin{array}{l}\text { - Não executam } \\
\text { a realização } \\
\text { da marcação } \\
\text { correta sobre o } \\
\text { adversário }\end{array}$ \\
\hline $\begin{array}{l}\text { Defensor do } \\
\text { atacante sem } \\
\text { posse de bola }\end{array}$ & $\begin{array}{l}\text { Movimentação } \\
\text { (marcação) }\end{array}$ & & $\begin{array}{l}\text { - Não se } \\
\text { preocupam com } \\
\text { seu marcador }\end{array}$ & \\
\hline
\end{tabular}

Fonte: os autores (2016)

A comparação entre os diagnósticos realizados pelo professor Danilo foi a que apresentou maior diferença. No primeiro, das seis dificuldades identificadas, cinco estavam relacionadas à execução de movimentos. No segundo, além de contemplar os quatro subpapéis, o educador identificou 12 problemas, sendo que a maioria deles correspondia a importantes intenções táticas que têm relação direta com o desempenho dos alunos no jogo. 
V. $29, n^{\circ} 50$, maio/2017

Quadro 5 - Matriz de análise dos diagnósticos realizados pelo professor Pedro

\begin{tabular}{|c|c|c|c|c|}
\hline \multirow{2}{*}{$\begin{array}{l}\text { Subpapéis nos } \\
\text { esportes de invasão }\end{array}$} & \multicolumn{2}{|c|}{$\begin{array}{l}\text { DIAGNÓSTICO REALIZADO } \\
\text { ANTES DO ESTUDO }\end{array}$} & \multicolumn{2}{|c|}{$\begin{array}{l}\text { DIAGNÓSTICO REALIZADO } \\
\text { APÓS O ESTUDO }\end{array}$} \\
\hline & $\begin{array}{l}\text { Dificuldades de } \\
\text { ordem tática }\end{array}$ & $\begin{array}{l}\text { Dificuldades de } \\
\text { ordem técnica }\end{array}$ & $\begin{array}{l}\text { Dificuldades de } \\
\text { ordem tática }\end{array}$ & $\begin{array}{l}\text { Dificuldades de } \\
\text { ordem técnica }\end{array}$ \\
\hline $\begin{array}{l}\text { Atacante com } \\
\text { posse de bola }\end{array}$ & $\begin{array}{l}\text { - Tomada de } \\
\text { decisão errada } \\
\text { - Leitura de } \\
\text { jogo } \\
\text { - Cabeça baixa }\end{array}$ & & $\begin{array}{l}\text { - Não observam } \\
\text { antes de agir } \\
\text { - Não passam para } \\
\text { o companheiro } \\
\text { em melhores } \\
\text { condições } \\
\text { - Não finalizam } \\
\text { no momento } \\
\text { adequado }\end{array}$ & $\begin{array}{l}\text { - Não executam } \\
\text { o passe } \\
\text { de forma } \\
\text { adequada }\end{array}$ \\
\hline $\begin{array}{l}\text { Atacante sem } \\
\text { posse de bola }\end{array}$ & & & $\begin{array}{l}\text { - Não se } \\
\text { desmarcam } \\
\text { - Não executam } \\
\text { cortes em L ou } \\
\text { em V }\end{array}$ & \\
\hline $\begin{array}{l}\text { Defensor do } \\
\text { atacante com posse } \\
\text { de bola }\end{array}$ & & & $\begin{array}{l}\text { - Não ficam } \\
\text { em uma linha } \\
\text { imaginária entre o } \\
\text { atacante e o gol }\end{array}$ & \\
\hline $\begin{array}{l}\text { Defensor do } \\
\text { atacante sem posse } \\
\text { de bola }\end{array}$ & & & $\begin{array}{l}\text { - Não se } \\
\text { responsabilizam } \\
\text { pelo atacante direto }\end{array}$ & \\
\hline
\end{tabular}

Fonte: os autores (2016)

O professor Pedro conseguiu perceber dificuldades dos alunos que não identificava antes do estudo. No primeiro diagnóstico, havia apontado três falhas que comprometiam o desempenho dos alunos no jogo. No segundo, conseguiu perceber mais do que o dobro, atendendo aos quatro subpapéis, vinculando sete dificuldades dos alunos à capacidade tática. 
Quadro 6 - Matriz de análise dos diagnósticos realizados pelo professor Ricardo

\begin{tabular}{|c|c|c|c|c|}
\hline \multirow{2}{*}{$\begin{array}{l}\text { Subpapéis nos } \\
\text { esportes de } \\
\text { invasão }\end{array}$} & \multicolumn{2}{|c|}{$\begin{array}{l}\text { DIAGNÓSTICO REALIZADO } \\
\text { ANTES DO ESTUDO }\end{array}$} & \multicolumn{2}{|c|}{$\begin{array}{l}\text { DIAGNÓSTICO REALIZADO } \\
\text { APÓS O ESTUDO }\end{array}$} \\
\hline & $\begin{array}{l}\text { Dificuldades de } \\
\text { ordem tática }\end{array}$ & $\begin{array}{l}\text { Dificuldades de } \\
\text { ordem técnica }\end{array}$ & $\begin{array}{l}\text { Dificuldades de } \\
\text { ordem tática }\end{array}$ & $\begin{array}{l}\text { Dificuldades de } \\
\text { ordem técnica }\end{array}$ \\
\hline $\begin{array}{l}\text { Atacante com } \\
\text { posse de bola }\end{array}$ & $\begin{array}{l}\text { - Erro de passe } \\
\text { (tomada de } \\
\text { decisão) }\end{array}$ & $\begin{array}{l}\text { - Dificuldade do } \\
\text { aluno com posse } \\
\text { de bola } \\
\text { - Dificuldades } \\
\text { nas variações dos } \\
\text { passes (quicado, } \\
\text { de peito, lateral) }\end{array}$ & $\begin{array}{l}\text { - Não observam } \\
\text { antes de agir } \\
\text { - Não passam } \\
\text { para o colega } \\
\text { desmarcado } \\
\text { - Não finalizam } \\
\text { no momento } \\
\text { adequado }\end{array}$ & $\begin{array}{l}\text { - Não executam } \\
\text { o movimento do } \\
\text { passe de maneira } \\
\text { correta } \\
\text { - Não executam } \\
\text { o movimento de } \\
\text { finalização de } \\
\text { maneira correta }\end{array}$ \\
\hline $\begin{array}{l}\text { Atacante sem } \\
\text { posse de bola }\end{array}$ & & & $\begin{array}{l}\text { - Não progridem } \\
\text { para o ataque } \\
\text { - Não se } \\
\text { desmarcam para } \\
\text { receber a bola }\end{array}$ & \\
\hline $\begin{array}{l}\text { Defensor do } \\
\text { atacante com } \\
\text { posse de bola }\end{array}$ & & & $\begin{array}{l}\text { - Linha imaginária } \\
\text { (não se } \\
\text { posicionam) } \\
\text { - Não retornam } \\
\text { para a defesa }\end{array}$ & \\
\hline $\begin{array}{l}\text { Defensor do } \\
\text { atacante sem } \\
\text { posse de bola }\end{array}$ & $\begin{array}{l}\text { - Marcação } \\
\text { muitas vezes } \\
\text { errada (não } \\
\text { marcam } \\
\text { individual) }\end{array}$ & & $\begin{array}{l}\text { - Não se } \\
\text { responsabilizam } \\
\text { pelo seu } \\
\text { marcador }\end{array}$ & \\
\hline
\end{tabular}

Fonte: os autores (2016)

Na comparação entre os diagnósticos, o docente Ricardo apresentou uma análise mais evoluída no segundo momento. Na primeira oportunidade, havia descoberto problemas relacionados a dois subpapéis, sendo dois de ordem tática e dois de ordem técnica. Após a realização do estudo, o professor evidenciou dez dificuldades dos alunos, sendo praticamente duas para cada subpapel.

Analisando os diagnósticos dos cinco educadores, de forma geral, é possível perceber como os resultados estão diretamente relacionados com a forma pela qual os professores compreendem os esportes. A partir do momento que os docentes ampliaram a visão, estudando uma série de temas relacionados ao universo esportivo, conseguiram perceber dificuldades na atuação dos alunos que não notavam antes do estudo. Esse achado é semelhante ao que foi percebido por Bracht et al. (2003), quando os autores identificaram que as distintas concepções dos docentes - relacionadas aos diferentes elementos do processo ensino-aprendizagem - regulam e influenciam a sua prática pedagógica. 


\section{CONCLUSÕES}

A mudança na capacidade de efetuar o diagnóstico permite ao professor ter um novo olhar sobre a atuação dos alunos em jogos esportivos de invasão. Essa ação oportuniza compreender os esportes com interação entre adversários como uma prática de ações imprevisíveis e de escolhas constantes durante a atuação no jogo, ao invés de um somatório de gestos motores.

A comparação entre os diagnósticos feitos pelos professores, da atuação de um grupo de alunos em um jogo esportivo, mostrou que na segunda observação todos os docentes conseguiram identificar mais do que o dobro das dificuldades percebidas na primeira análise. Desses entraves, a maioria se vinculavam à dimensão tática, o que coincide com a análise que realizamos do mesmo jogo.

Esse fato permite observar como as possibilidades de diagnóstico de um jogo com interação entre adversários são condicionadas pela compreensão da lógica interna das práticas motoras. Ou seja, a capacidade de identificar problemas na atuação dos alunos está relacionada à forma como o docente compreende o esporte. A partir do momento em que os educadores passaram a perceber a dimensão tática do jogo, conseguiram identificar o que antes não enxergavam.

Nesse sentido, o nível de leitura das dificuldades dos alunos no jogo depende diretamente de como o professor percebe o processo de ensino dos esportes. Pois, docentes que compreendem o esporte na perspectiva do modelo tradicional, tendem a identificar apenas dificuldades na execução dos movimentos. Entendendo que o diagnóstico é uma importante ferramenta para aferir os problemas dos discentes no jogo, os entraves a serem identificados pelos docentes dependem diretamente da sua concepção de esporte. Logo, a forma como o educador compreende a lógica interna das práticas motoras, influenciará na identificação das dificuldades dos alunos.

Pautando-se nas evidências desse estudo, concluímos que é possível alterar a capacidade de os professores identificarem problemas que limitam a atuação dos alunos em jogos esportivos. Dito de outra forma, docentes que durante a realização da leitura do jogo identificam apenas entraves vinculados a gestos motores, podem mudar sua capacidade de perceber a origem das dificuldades dos jogadores, notando problemas de tomada de decisão que não percebiam anteriormente. No caso específico dessa investigação, o período de estudo alterou o quadro de referência para a análise do jogo. Essa situação, possibilita selecionar conteúdos de ensino alinhados às dificuldades dos alunos que prejudicam/ limitam uma atuação mais qualificada nos jogos esportivos.

\section{REFERÊNCIAS}

BAYER, C. O ensino dos desportos coletivos. Lisboa: Dinalivro, 1994.

COUTINHO, N. F.; SILVA, S. A. Conhecimento e aplicação de métodos de ensino para os jogos esportivos coletivos na formação profissional em educação física. Movimento, Porto Alegre, v. 15, n. 1, p. 117-144, jan./mar. 2009. 
CÔTÉ, J.; HANCOCK, D. Evidence-based policies for youth sports programmes. International Journal of Sport Policy and Politics, 2014.

BETTI, M. Imagens em avaliação-ação: uma pesquisa-ação sobre o uso de matérias televisivas em aulas de educação física. Educar em Revista, Curitiba, n. especial 2, p. 137-152, 2010.

. Educação física escolar: ensino e pesquisa-ação. ljuí: Ed. Unijuí, 2013.

BRACHT, V. et al. Pesquisa em ação: a educação física na escola. ljuí: Unijuí, 2003.

FERREIRA, H. B. Pedagogia do esporte: identificação, discussão e aplicação de procedimentos pedagógicos no processo de ensino-vivência e aprendizagem da modalidade basquetebol. 2009. 240f. Dissertação (Mestrado em Educação Física) Faculdade de Educação Física, Universidade Estadual de Campinas, Campinas, 2009. FRANCO, M. A. S. Pedagogia da pesquisa-ação. Educação e pesquisa, São Paulo, v. 31, n. 3, p. 483-502, set./dez. 2005.

GARGANTA, J. M. Para uma teoria dos jogos desportivos coletivos. In: GRAÇA, A; OLIVEIRA, J. (Org.). O ensino dos jogos desportivos coletivos. Lisboa: Universidade do Porto, 1998. p. 11-25.

. A formação estratégico-tática nos jogos desportivos de oposição e cooperação. In: GAYA, A.; MARQUES, A.; TANI, G. (Org.). Desporto para crianças e jovens: razões e finalidades. Porto Alegre: Universidade Federal do Rio Grande do Sul, 2004. p. 217-233. . Ideais e competências para "pilotar" o jogo de futebol. In: TANI, G.; BENTO, J. O.; PETERSEN, R. D. S. (Org.). Pedagogia do desporto. Rio de Janeiro: Guanabara Koogan, 2006. p. 313-326.

GONZÁLEZ, F. J. Metodologia do Ensino dos Esportes II. Ijuí: Unijuí, 2008. [Mimeografado]. ; FENSTERSEIFER, P. E. Entre o "não mais" e o "ainda não": pensando saídas do não lugar da EF escolar I. Cadernos de formação RBCE, p. 9-24, set. 2009.

GONZÁLEZ, F. J.; BRACHT, V. Metodologia do ensino dos esportes coletivos. Vitória:

UFES, Núcleo de Educação Aberta e a Distância, 2012.

GONZÁLEZ, F. J; FRAGA, A. B. Afazeres da educação física na escola: planejar, ensinar, partilhar. Erechim: Edelbra, 2012.

GONZÁLEZ, F. J.; BORGES, R. M. Diálogos sobre o ensino dos esportes da educação física escolar: uma pesquisa-ação na formação continuada. Motrivivência, v. 27, n. 45, 2015. p. 172-188.

GRAÇA, A. Modelos e conceções de ensino dos jogos desportivos. In: TAVARES, F. (Org.).

Jogos desportivos coletivos: ensinar a jogar. Portugal: FADEUP, 2013. p. 9-54.

; MESQUITA, I. M. R. Ensino do desporto. In: TANI, G.; BENTO, J. O.; PETERSEN,

R. D. S. (Org.). Pedagogia do desporto. Rio de Janeiro: Guanabara Koogan, 2006. p. 207-218.

. Modelos e conceções de ensino dos jogos desportivos. In: TAVARES, F. (Org.).

Jogos desportivos coletivos: ensinar a jogar. Portugal: FADEUP, 2013. p. 9-54.

GRIFFIN, L.; MITCHELL, S. A.; OSLIN, J. L. Teaching Sport Concepts and Skills: a tactical games approach. Champaign: Human Kinetics, 1997. 
V. $29, \mathrm{n}^{\circ}$ 50, maio/2017

KIRK, D.; MACPHAIL, A. Teaching games for understanding and situated learning: rethinking the Bunker-Thorpe model. Journal of Teaching in Physical Education, v. 2, n. 21, p. 177-192, 2002.

LIGHT, R.; TAN, S. Culture, embodied experience and teachers' development of TGfU in Australia and Singapore. European Physical Education Review, v. 12, n. 1, 2006, p. 99-117.

MESQUITA, I. M. R. Perspectiva construtivista da aprendizagem no ensino do jogo. In: NASCIMENTO, J. V.; RAMOS, V.; TAVARES, F. (Org.). Jogos desportivos: formação e investigação. Florianópolis: UDESC, 2013. v. 4, p. 103-131.

RAMOS, V.; GRAÇA, A. B. S.; NASCIMENTO, J. V. A representação do ensino do basquetebol em contexto escolar: estudos de casos na formação inicial em educação física. Revista Brasileira de Educação Física e Esporte, São Paulo, v. 20, n. 1, p. 3749, jan/mar. 2006.

SIEDENTOP, D. Sport Education: a retrospective. Journal of Teaching in Physical Education, v. 21, p. 409-418, 2002.

SILVERMAN, D. Interpretação de dados qualitativos: métodos para análise de entrevistas, textos e interações. Porto Alegre: Artmed, 2009.

TAVARES, F. Jogos desportivos coletivos: contributos para a sua análise e funcionamento. In: RAMOS, V.; SAAD, M.; MILISTETD, M. (Org.). Jogos desportivos: investigação e prática pedagógica. Florianópolis: UDESC, 2013. v. 3, p. 17-51.

THIOLLENT, M. Metodologia da pesquisa-ação. São Paulo: Cortez, 2011.

TRIPP, D. Pesquisa-ação: uma introdução metodológica. Educação e Pesquisa, São Paulo, v. 31, n. 3, p. 443-466, set./dez. 2005.

ZABALA, A. A prática educativa: como ensinar. Porto Alegre: Editora Artes Médicas Sul Ltda, 1998. 


\title{
POSSIBILITIES OF REALIZATION OF DIAGNOSIS IN EDUCATION SPORTS: An action research with teachers of Physical Education
}

\begin{abstract}
This study aimed to describe how the diagnostic possibilities for a game with interaction between opponents are conditioned by the understanding of sports internal logic. Therefore, an action research with five physical education teachers who develop the teaching of sports was developed. 21 study meetings were held on the decision of what to teach when the focus is on the procedural knowledge of the content. The results indicate that the reading level of students' difficulties in the game depends directly on the teacher's knowledge of the internal logic of the arrangements, which affects the learning of students. However, you can change the way teachers understand the sports school, so that teachers who perform the reading of the game from the perspective of the traditional model to understand the sport phenomenon as a complex process of decision-making, teaching students play better.
\end{abstract}

Keywords: Sport; Teaching Design; Diagnosis; Change

\section{POSIBILIDADES DE REALIZACIÓN DE DIAGNÓSTICO EN EDUCACIÓN DEPORTES: Una investigación-acción con los profesores de Educación Física}

\section{RESUMEN}

Este estudio tuvo como objetivo describir cómo las posibilidades de diagnóstico para un juego con la interacción entre los oponentes están condicionadas por la comprensión de los deportes lógica interna. Por lo tanto, se desarrolló una investigación-acción con cinco profesores de educación física que desarrollan la enseñanza de los deportes. 21 sesiones de estudio se llevaron a cabo en la decisión de qué enseñar cuando la atención se centra en el conocimiento de los procedimientos de los contenidos. Los resultados indican que el nivel de lectura de dificultades de los estudiantes en el juego depende directamente del conocimiento del profesor de la lógica interna del régimen, lo que afecta el aprendizaje de los estudiantes. Sin embargo, puede cambiar la forma de los maestros a entender la escuela deportiva, por lo que los maestros que realizan la lectura del juego desde la perspectiva del modelo tradicional de entender el fenómeno deportivo como un complejo proceso de toma de decisiones, la enseñanza de los estudiantes jugar mejor.

Palabras clave: Deporte; La Enseñanza del Diseño; Diagnóstico; Cambio 